\title{
The effect of drill-pipe rotation on improving hole cleaning using polypropylene beads in water-based mud at different hole angles
}

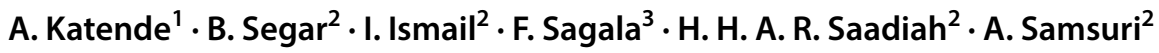

Received: 31 May 2019 / Accepted: 24 November 2019 / Published online: 5 December 2019

(c) The Author(s) 2019

\begin{abstract}
Hole cleaning is always a problem, particularly during drilling operations, and drilling fluid plays an important role in transporting drill cuttings through an annular section of wellbore to the surface. To transport the cuttings, a water-based mud with added polypropylene beads was selected since it is environmentally friendly and cost efficient. The polypropylene beads help to transport cuttings by providing an additional buoyancy force that lifts the cuttings to the surface via the influence of collision and drag forces. This experiment was performed using a $20 \mathrm{ft}$ test section, $10 \mathrm{ppg}$ drilling mud and $0.86 \mathrm{~m} / \mathrm{s}$ annular velocity in a laboratory scale rig simulator, and the concentration of polypropylene beads was varied from 0 to $8 \mathrm{ppb}$. As the concentration of polypropylene increases, the cutting transport ratio also increases. It was observed that the fewest cuttings are lifted at a critical angle of $60^{\circ}$, followed by $45^{\circ}, 30^{\circ}, 90^{\circ}$ and $0^{\circ}$. Additionally, cutting sizes had moderate effects on the cutting lifting efficiency, where smaller cutting sizes $(0.5-1.0 \mathrm{~mm})$ are easier to lift than larger cutting sizes $(2.0-2.8 \mathrm{~mm})$. Furthermore, a study of buoyancy force and impulsive force was conducted to investigate the cutting lifting efficiencies of various concentrations of polypropylene beads. This lifting capacity was also assisted by the presence of polyanionic cellulose (PAC), which increases the mud carrying capacity and is effective for smaller cuttings. The results show that in the presence of pipe rotation, the cutting lifting efficiency is slightly enhanced due to the orbital motion provided by the drill pipe for better hole cleaning. In conclusion, polypropylene beads combined with pipe rotation increase the cutting transport ratio in the wellbore.
\end{abstract}

Keywords Hole cleaning $\cdot$ Cutting transport ratio $\cdot$ Hole angles $\cdot$ Pipe rotation $\cdot$ Water-based mud $\cdot$ Cutting size

$\begin{array}{ll}\text { Abbreviation } \\ \text { OBM } & \text { Oil-based mud } \\ \text { SBM } & \text { Synthetic-based mud } \\ \text { WBM } & \text { Water-based mud } \\ \text { CTR } & \text { Cuttings transport ratio } \\ \text { RPM } & \text { Revolutions per minute } \\ \text { MTV } & \text { Minimum transport velocity } \\ F_{\text {B }} & \text { Buoyancy force } \\ \mathrm{g} & \text { Acceleration due to gravity } \\ \mathrm{m} & \text { Mass of particle }\end{array}$

I. Ismail

issham@utm.my

1 Oklahoma State University, 420 Engineering North, Stillwater, OK 74078, USA

2 Department of Petroleum Engineering, Faculty of Chemical and Energy Engineering, Universiti Teknologi Malaysia, 81310 Skudai, Iskandar Puteri, Johor, Malaysia

3 Department of Chemical and Petroleum Engineering, University of Calgary (UC), Calgary, Canada

$\begin{array}{ll}V_{p} & \text { Particle velocity } \\ V_{f} & \text { Particle final velocity } \\ V_{i} & \text { Particle initial velocity } \\ \text { PAC } & \text { Polyanionic cellulose } \\ \text { COF } & \text { Coefficient of friction } \\ \text { CFD } & \text { Computational fluid dynamics } \\ \text { CFD-DEM } & \text { Computational fluid dynamics-discrete-ele- } \\ & \text { ment method }\end{array}$

\section{Introduction}

Drilling fluids have routinely been used in the oil and gas industry for several years, and such fluids have served many roles, such as balancing formation pressures in the wellbore, lubricating the drill string and so forth (Beck et al. 1947; Bland et al. 2006; Duan et al. 2008; Hussaini and Azar 1974; Katende et al. 2019; Ozbayoglu et al. 2010; Pigott 1941; Saboori et al. 2018; Salehi et al. 2016; Saxena et al. 2017; Sayindla et al. 2017; Shu and Ma 2016; 
Sifferman et al. 1974; Werner et al. 2017). Nevertheless, an essential role of drilling fluid is to lift cuttings from the drill bit through the annular section and to the surface (Becker and Azar 1985; Clark and Bickham 1994; Frigaard et al. 2017; Heshamudin et al. 2019; Luo et al. 1994; Majid et al. 2018; Onuoha et al. 2015; Shu and Zhang 2018a, b; Yu et al. 2004). It is difficult to proceed with the drilling process without removing the cuttings. For vertical wells, cutting lifting can typically proceed without any difficulties, but for a deviated well, there are difficulties in transporting the cuttings because they may accumulate, forming either a stationary bed at hole angles greater than $50^{\circ}$ or a moving bed at lower angles (Williams and Bruce 1951). Hence, the seriousness of cutting lifting varies depending on the amount and the location of cuttings distributed along the wellbore (Clark and Bickham 1994; Egenti 2014; Hareland et al. 1993; Kamyab and Rasouli 2016; Nazari et al. 2010; Pang et al. 2019; Zeng et al. 2018b).

With directional drilling and extended-reach wells becoming popular, factors such as increased torque and drag force have become increasingly more significant (Amanna et al. 2016; Dushaishi et al. 2016; Frank and Ting 2014; Gavignet and Sobey 1989; Hovda 2019; Mamat et al. 2013; Piroozian et al. 2012; Yan et al. 2018a, b; Zeng et al. 2018a). This is particularly true for waterbased muds (WBMs), which generate a high coefficient of friction (COF) between the drill string and the wellbore, resulting in higher torque and drag force.

In addition, WBMs are able to amplify the wear rates in the wellbore. Oil-based muds (OBMs) and synthetic-based muds (SBMs) typically generate a lower COF compared to WBMs, particularly when they involve contact between the formation and steel. Nevertheless, the use of OBMs and SBMs is restricted due to their high costs and environmental effects. Furthermore, drilling fluids can impact wellbore integrity due to cement contamination during drilling (Li and Radonjic 2019). It will therefore be better to develop environmental friendly WBMs that are as lubricious as OBMs and SBMs (Growcock et al. 1999). With the technical application and economic benefits of drilling wells at high angles, especially from a vertical level, there has been a problem in controlling the behavior of drill cuttings in the well, which has proven to be costly.

Moreover, we lack the ability to control annular environments Becker and Azar (1985). In addition to transporting cuttings, the distribution of cuttings in the wellbore is affected not only by pipe rotation but also cutting sizes and fluid properties, especially in eccentric situations (Ozbayoglu et al. 2004, 2008; Peden et al. 1990; Sanchez et al. 1999; Walker and Li 2000). In general, the presence of pipe rotation will gradually reduce stationary cutting beds in the wellbore. The circular motion of the drill string may be the basis for the effect of inclination on pressure drop, even though no cuttings are visible.

Normally, the mixing of polymer beads, such as polypropylene beads, with WBM has proven (Hakim et al. 2018; Yeu et al. 2019; Yi et al. 2017) to be successful in reducing the slip velocity of cuttings, which makes the polymer bead buoyant in the mud, thus causing a reduction in the Reynolds number of particles. The decrease in the Reynolds number of particles results in an increase in drag force (Bird and Garrett 1996; Skalle 2010; Williams and Bruce 1951). The increase in drag force results in better mud lifting capacity for a good wellbore cleaning at various angles, such as vertical, horizontal and even deviated conditions (Onuoha et al. 2015; Ozbayoglu et al. 2004).

Hakim et al. (2018) investigated the performances of polyethylene and polypropylene beads in transporting drill cuttings in a horizontal wellbore. Their analysis involved using a mud formulation reported by Scomi (2018), to observe the effect of polymer beads on hole cleaning. The results showed that polymer beads improved the hole cleaning efficiency.

From these studies (Akhshik et al. 2015; Bilgesu et al. 2007; Boyou et al. 2019; Hemphill and Ravi 2010; Moraveji et al. 2017; Oseh et al. 2019; Ozbayoglu et al. 2008; Pang et al. 2018; Peden et al. 1990; Rooki et al. 2018; Sanchez et al. 1999; Sun et al. 2014), the following question arises: to what extent does the effect of pipe rotation improve hole cleaning using polypropylene beads in WBM at different hole angles? This question forms the basis of this study to clarify the effect of pipe rotation on hole cleaning at different hole angles. This is because polypropylene beads provide a buoyancy force, which would provide an additional lifting capacity in the form of collision and drag in the drilling fluid due to their less dense nature that aids in lifting cuttings in a highly efficient manner from the wellbore to the surface.

\section{Experimental setup and methods}

The purpose of this study is to investigate the effect of pipe rotation on cutting lifting efficiency using different concentrations of polypropylene beads in WBM at different hole angles. This study was conducted in two stages. The first stage involved the use of basic WBM, and the second stage was performed using five different concentrations $(0,2,4$, 6 and $8 \mathrm{ppb}$ ) of polypropylene beads. Each stage was conducted using five different hole angles $\left(0^{\circ}, 30^{\circ}, 45^{\circ}, 60^{\circ}\right.$ and $\left.90^{\circ}\right)$ and in the presence of pipe rotation $(0$ and 120 RPM) to determine the effect of hole angle on cutting lifting efficiency. 


\section{Laboratory scale flow loop rig simulator}

A laboratory scale flow loop rig simulator (Fig. 1) was used to investigate the effect of pipe rotation using polypropylene beads in WBM at different hole angles.

\section{Material preparation}

\section{Sand samples}

The sand samples were collected, washed and heated in an oven for $24 \mathrm{~h}$ at $60^{\circ} \mathrm{C}$. After heating, the sand samples were sieved using a sieve shaker to obtain the desired particle sizes. Different sizes of sieve trays $(4.00,2.80,2.00,1.70$, $1.40,1.00$ and $0.50 \mathrm{~mm}$ ) were used to obtain different cutting size ranges $(0.50-0.99 \mathrm{~mm}, 1.00-1.39 \mathrm{~mm}, 1.40-1.69$ $\mathrm{mm}, 1.7-1.99 \mathrm{~mm}, 2.00-2.79 \mathrm{~mm}$ and $2.80-4.00 \mathrm{~mm}$ ). The sieved sands were then weighed using an electronic balance and placed in sealable plastic bags.

\section{Polypropylene beads}

Figure 2 shows the polypropylene beads used in this study. Polypropylene beads are used to provide buoyancy force to improve cutting lifting efficiency. Moreover, the beads are spherical, opaque and have a density of $0.90 \mathrm{~g} / \mathrm{cc}$, and their size ranges from $2-3 \mathrm{~mm}$. The beads are inert; thus, they do not chemically react with the drilling fluid. The beads can also be recycled for upcoming operations. Four concentrations of polymer beads $(2,4,6$ and $8 \mathrm{ppb})$ were added to the WBM.

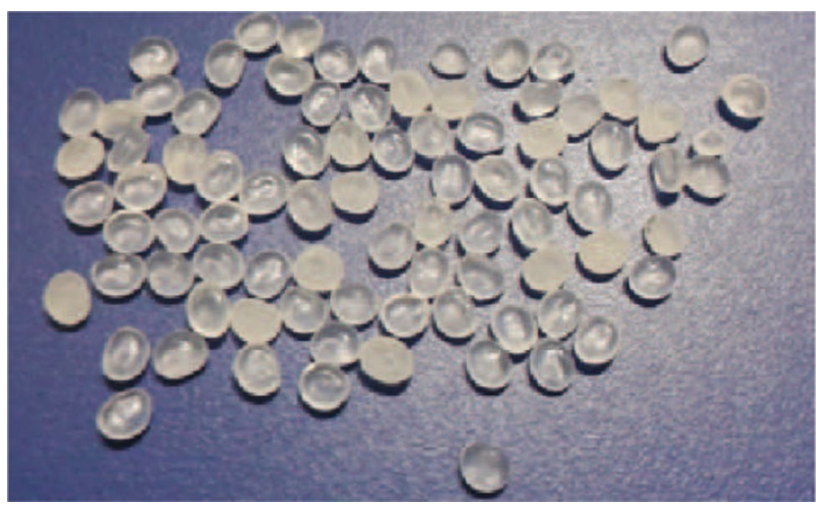

Fig. 2 Polypropylene beads

\section{Drilling mud}

The experiment was performed with five different concentrations of polypropylene beads with Miswaco (2018) mud formulation. To simulate the actual drilling fluid being used in the oil and gas industry for deep water drilling operations, a density of 10 pounds per gallon (ppg) was set to prepare the basic WBM in Table 1.

To obtain the desired mud density, barite was added to each lab barrel for each concentration of polypropylene beads, as listed in Table 2 .

\section{Experimental procedure}

The experiment was conducted using a laboratory scale rig simulator at ambient temperature. The experimental procedure was adapted to determine the effects of pipe rotation

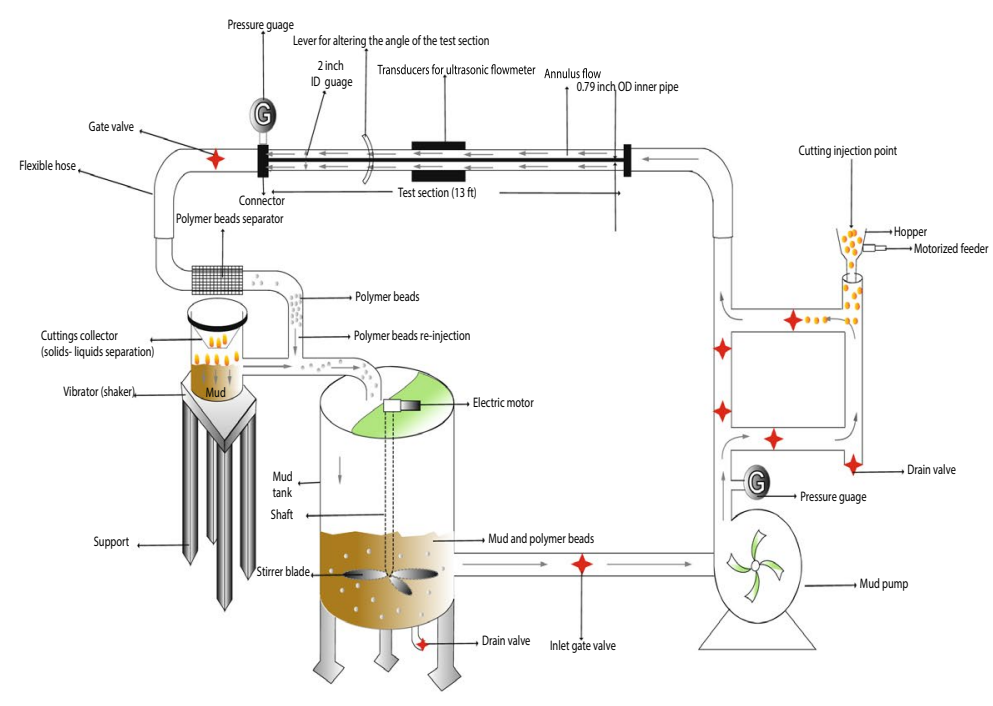

(a) Schematic of the flow loop Rig Simulator

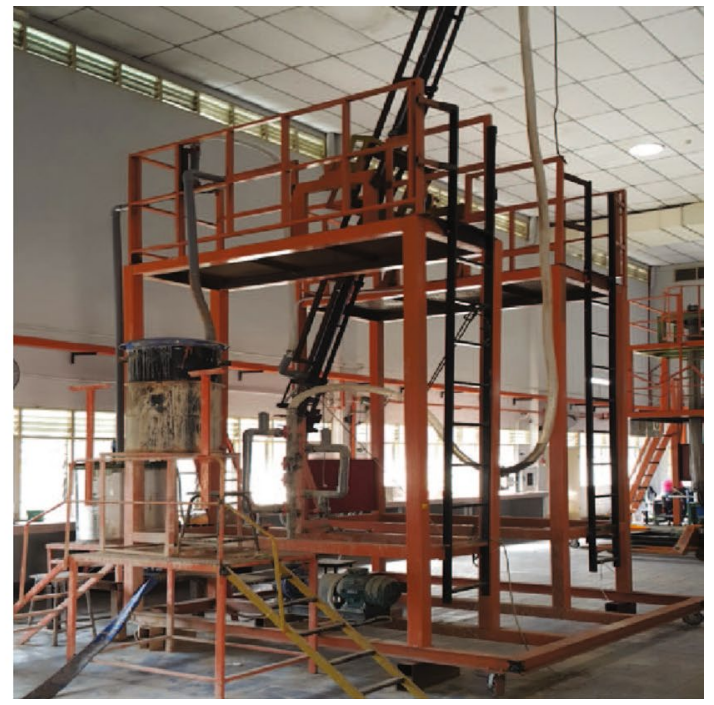

(b) Lay out of the Flow Loop Rig Simulator.

Fig. 1 Flow loop rig simulator 
Table 1 Water-based mud formulation

\begin{tabular}{ll}
\hline Additives & Composition \\
\hline Fresh water & $150 \mathrm{~L}$ \\
Bentonite & $4285.71 \mathrm{~g}$ \\
Caustic soda & $107.14 \mathrm{~g}$ \\
PAC-HV & $214.29 \mathrm{~g}$ \\
Xanthan gum & $321.43 \mathrm{~g}$ \\
Barite & $39840.00 \mathrm{~g}$ \\
\hline
\end{tabular}

Table 2 Weight of barite needed for different polypropylene concentrations

\begin{tabular}{ll}
\hline Type of Mud & $\begin{array}{l}\text { Weight } \\
\text { of Barite } \\
\text { Added(g) }\end{array}$ \\
\hline WBM & 39840.00 \\
WBM + 2 ppb Polypropylene beads & 39334.29 \\
WBM + 4 ppb Polypropylene beads & 40088.57 \\
WBM + 6 ppb Polypropylene beads & 40092.86 \\
WBM + 8 ppb Polypropylene beads & 40594.29 \\
\hline
\end{tabular}

on hole cleaning using polypropylene beads at different hole angles in WBM. Before starting the experiment, all the parts of the rig simulator (Fig. 1) were examined to avoid any leakage of drilling fluid and to ensure that each part is completely sealed to avoid contamination. As mentioned previously, the study was conducted in two stages, which required two types of drilling mud systems to be used, where basic WBM and five different concentrations of polypropylene beads $(0,2,4,6$ and $8 \mathrm{ppb})$ were used.

To test the cutting lifting ability of basic mud, the test section was set at $0^{\circ}$ (vertical angle) and without any pipe rotation; the basic mud was circulated in the flow loop system until it achieved stabilization. Then, cuttings were injected into the system and flowed for approximately $5 \mathrm{~min}$. Subsequently, the valve connecting to the separation unit was opened and allowed to flow for $7 \mathrm{~min}$ to determine the cutting lifting efficiency of basic mud at $0^{\circ}$ without any pipe rotation.

After $7 \mathrm{~min}$, the valve was immediately closed, and the lifted cuttings were collected, washed, dried, weighed and recorded. The dried cuttings were reused and injected into the flow loop. The experiment was repeated using different hole angles $\left(30^{\circ}, 45^{\circ}, 60^{\circ}\right.$ and $\left.90^{\circ}\right)$ by following the same procedure mentioned previously without any pipe rotation. Once the data for all hole angles were collected, the same procedure was repeated with pipe rotation.

After completing the first stage, the same procedure was used for the second stage, where the basic mud was mixed with different concentrations of polypropylene beads. At the end of each run, the mud system was flushed to the separation unit to retrieve the cuttings and polypropylene beads manually before proceeding with different concentrations of beads. At the separation unit, the sieve acts as a medium to trap both cuttings and polypropylene beads, where both of them were placed in a pail of water. Due to their lower density, the beads tend to float, and the cuttings settle at the bottom of the pail. Then, the cuttings were obtained, washed, dried and weighed.

The collected data were recorded, and the cutting transport ratio (CTR) was calculated using Eq. 1. Hence, the CTRs of all hole angles were compared and analyzed for their efficiency in lifting cuttings.

$$
\begin{aligned}
& \text { CTR },(\%) \\
& =\frac{\text { Recovered injected drilled cuttings }}{\text { Initial injected drilled cuttings }} \\
& \times 100
\end{aligned}
$$

\section{Results and discussion}

\section{Performance of polypropylene beads at different angles without pipe rotation}

A plot of CTR versus hole angle was analyzed, as shown in Fig. 3 (cutting size of $0.5-1.0 \mathrm{~mm}$ ) and Fig. 4 (cutting size of $2.0-2.8 \mathrm{~mm}$ ). For smaller cuttings, the CTR was found to be the lowest at $60^{\circ}$, followed by $45^{\circ}, 90^{\circ}, 30^{\circ}$ and $0^{\circ}$. According to Peden et al. (1990) and Clark and Bickham (1994), the minimum transport velocity (MTV) is the highest at hole angles from $40^{\circ}$ to $60^{\circ}$, and it experiences a drastic reduction at hole angles above $60^{\circ}$. This behavior occurs because at lower angles (below $60^{\circ}$ ), the

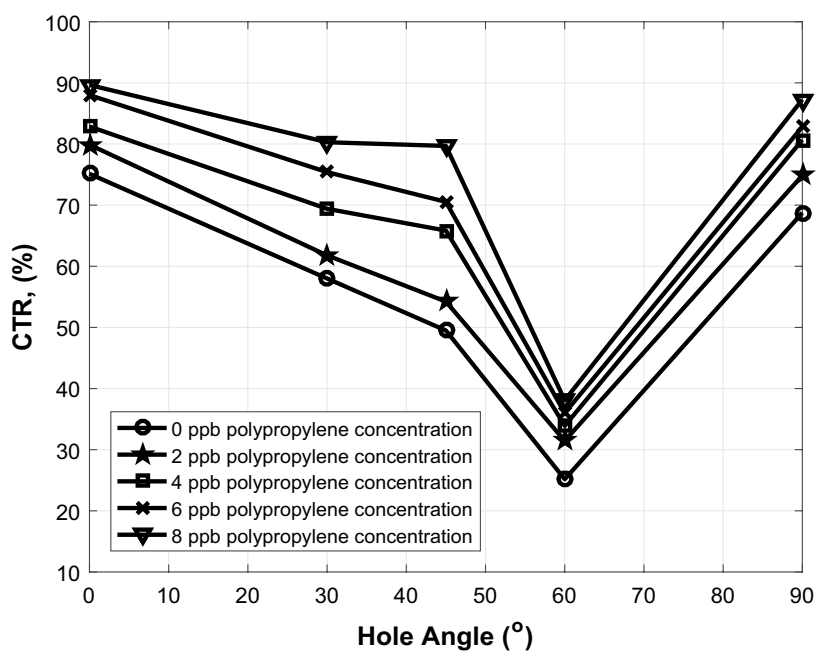

Fig. 3 Cutting transport ratio vs. hole angle for cuttings size of $0.5-$ $1.0 \mathrm{~mm}$ and pipe rotation of $0 \mathrm{RPM}$ 


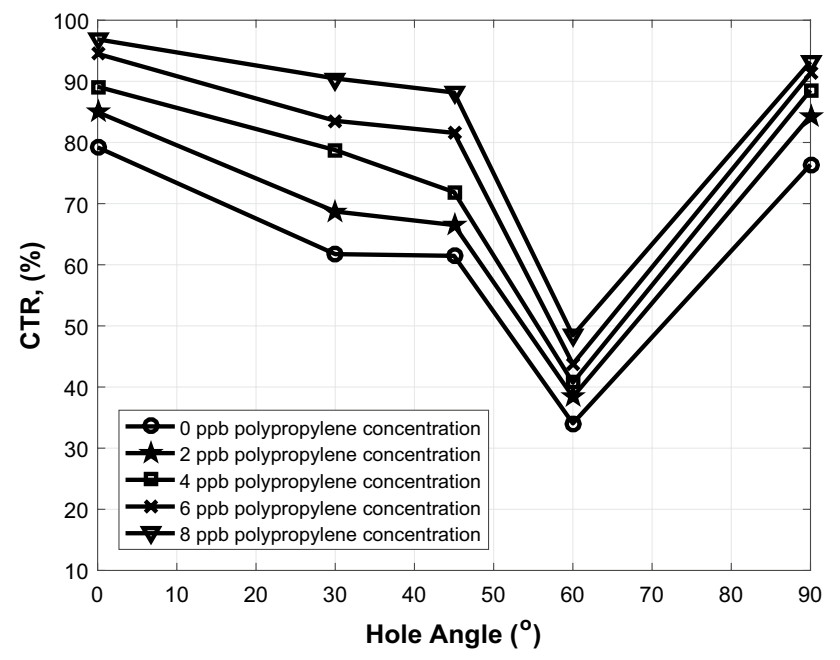

Fig. 4 Cutting transport ratio vs. hole angle for cuttings size of 2.0$2.8 \mathrm{~mm}$ and pipe rotation of $0 \mathrm{RPM}$

cuttings experience a lifting mechanism, which requires a higher MTV to lift the cuttings, and the mechanism shifts into a rolling mechanism at higher angles (above $60^{\circ}$ ), which requires a lower MTV for better cutting lifting. The CTR at the critical angle of $60^{\circ}$ ranges from $54.5 \%$ to 63.4 $\%$. In addition, the CTR for the least critical angle of $0^{\circ}$ ranges from $84.1 \%$ to $89.2 \%$. At the horizontal angle, the CTR ranges from $74.1 \%$ to $81.7 \%$, which is lower than that of the vertical angle. Hole angle has minor effects on stationary bed formation at angles from $70^{\circ}$ to $90^{\circ}$ (Duan et al. 2008).

As shown in Fig. 4 (cutting size of 2.0-2.8 mm), the CTR was the lowest at $60^{\circ}$, followed by $45^{\circ}, 30^{\circ}, 90^{\circ}$ and $0^{\circ}$. For larger cutting sizes, the CTR was significant at the vertical angle because larger cuttings experience less drag and torque compared to smaller cuttings $(0.5-1.0 \mathrm{~mm})$. Smaller cuttings experience a lower MTV for cutting rolling/sliding, and stationary bed formation decreases, which results in a higher cutting transportation compared to larger cuttings (Duan et al. 2008).

Peden et al. (1990) determined that larger cuttings are more difficult to transport, especially at angles above $60^{\circ}$. The CTR at the critical angle of $60^{\circ}$ ranges from $25.2 \%$ to $38.1 \%$. Moreover, the CTR for the least critical angle of $0^{\circ}$ ranges from $75.1 \%$ to $89.7 \%$. At the horizontal angle, the CTR ranges from $68.8 \%$ to $87.3 \%$, which is less than that of the vertical angle due to the formation of sand dunes.

In addition, the increase in the concentration of polypropylene beads causes a significant increase in the CTR for both cutting sizes (Figs. 3 and 4). At $0.5-1.0 \mathrm{~mm}$, the CTR for the vertical angle increases from $85.2 \%$ at $0 \mathrm{ppb}$ to $87.4 \%$ at $6 \mathrm{ppb}$. Meanwhile, at $2.0-2.8 \mathrm{~mm}$, the CTR at the vertical angle increases from $75.1 \%$ to $88.0 \%$. This result indicates that polypropylene beads do provide an increase in cutting lifting efficiency regardless of the hole angle.

\section{Performance of Polypropylene Beads at Different Angles with Pipe Rotation}

In Figs. $5(0.5-1.0 \mathrm{~mm})$ and $6(2.0-2.8 \mathrm{~mm})$, the CTR versus hole angle graph is plotted and analyzed for a pipe rotation of 120 RPM. The hole angle pattern remains similar to Figs. 3 and 4 , where $60^{\circ}$ is the most critical angle, and the least critical angle for both cutting sizes is $0^{\circ}$. However, there is a significant increase in the CTR value due to the presence of pipe rotation. For example, at the critical angle,

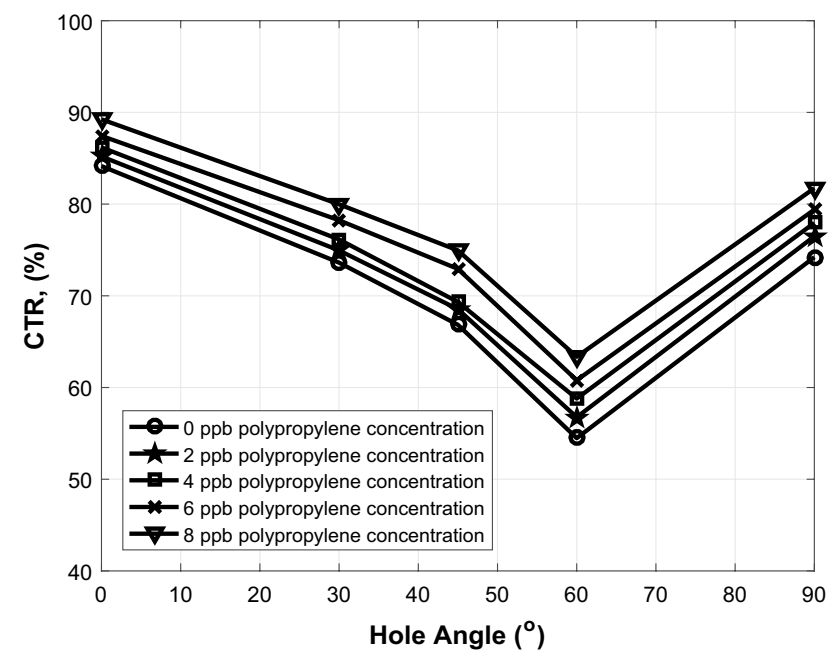

Fig. 5 Cutting transport ratio vs. hole angle for cuttings size of $0.5-$ $1.0 \mathrm{~mm}$ and pipe rotation of $120 \mathrm{RPM}$

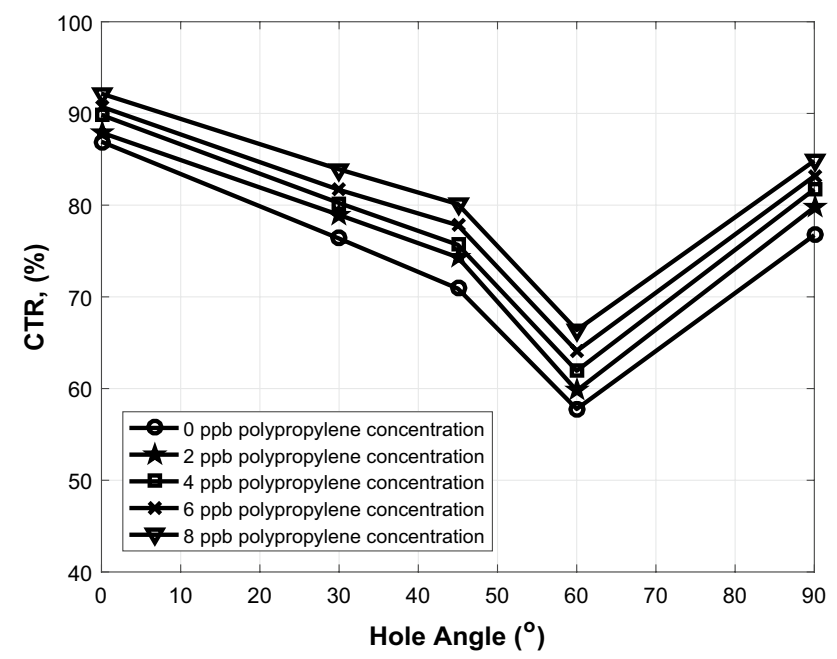

Fig. 6 Cutting transport ratio vs. hole angle for cuttings size of 2.0$2.8 \mathrm{~mm}$ and pipe rotation of $120 \mathrm{RPM}$

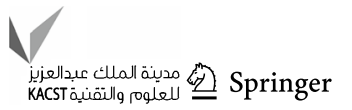


the CTR value for smaller cuttings increases from $54.5 \%$ to $57.8 \%$ and increases from $25.2 \%$ to $34.1 \%$ for larger cuttings at $0 \mathrm{ppb}$. The CTR for the least critical angle of $0^{\circ}$ increases from $84.1 \%$ to $86.9 \%$ for smaller cuttings at 0 ppb and increases from $75.1 \%$ to $79.2 \%$ for larger cuttings at $0 \mathrm{ppb}$. This result is due to the orbital motion of the drill pipe that reduces the concentration of cuttings in the lower annular section that causes a mechanical agitation, which lifts the cuttings to the surface (Sanchez et al. 1999).

As shown in Figs. 5 and 6, the presence of polypropylene beads aids in increasing the cutting lifting efficiency for both cutting sizes. At $0.5-1.0 \mathrm{~mm}$, the CTR for the vertical angle increases from $86.9 \%$ at $0 \mathrm{ppb}$ to $90.7 \%$ at $6 \mathrm{ppb}$ for 120 RPM. Meanwhile, at $2.0-2.8 \mathrm{~mm}$, the CTR at the vertical angle increases from $79.2 \%$ at $0 \mathrm{ppb}$ to $96.1 \%$ at 6 ppb for 120 RPM. Thus, this result confirms that the presence of pipe rotation aided by the increased concentration of polypropylene helps to improve the transport of cuttings at all hole angles.

\section{Comparison between smaller and larger cutting sizes at the critical angle of $60^{\circ}$}

Figures 7 and 8 show that the smallest cutting size $(0.5-1.0 \mathrm{~mm})$ lifted the most cuttings from $0 \mathrm{ppb}$ to $8 \mathrm{ppb}$ (54.5-63.4\%) compared to the largest cutting size (2.0-2.8 $\mathrm{mm})$, which lifted the fewest cuttings ( $25.2 \%-38.1 \%)$, at the critical angle of $60^{\circ}$ without the presence of pipe rotation. This result might be due to the viscous drilling mud, which contains polyanionic cellulose (PAC), a viscosifying agent. In the presence of PAC solutions that increase the mud carrying capacity, smaller cuttings are greatly

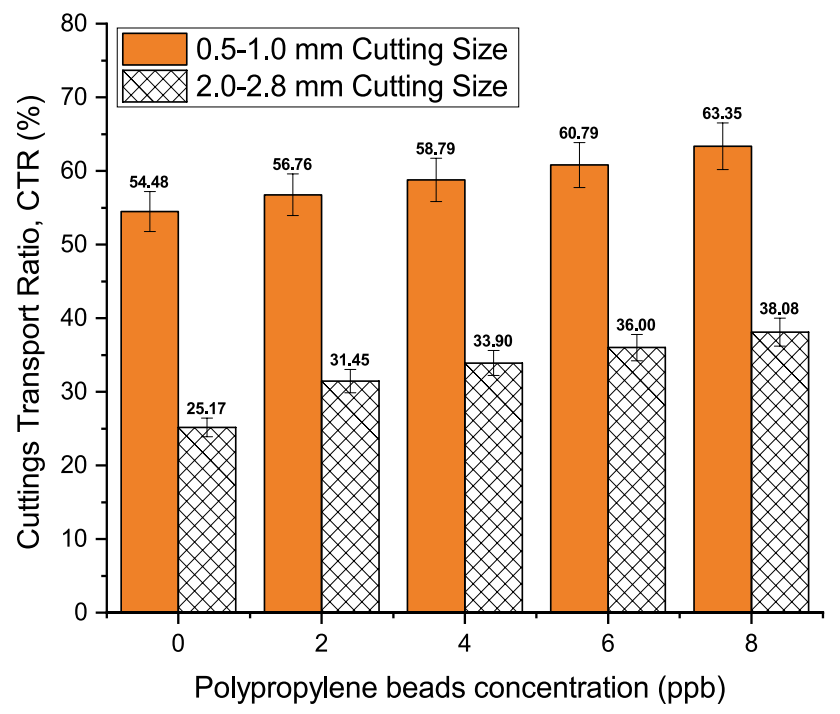

Fig. 7 CTR versus polypropylene bead concentration for both cuttings sizes without pipe rotation (0 RPM)

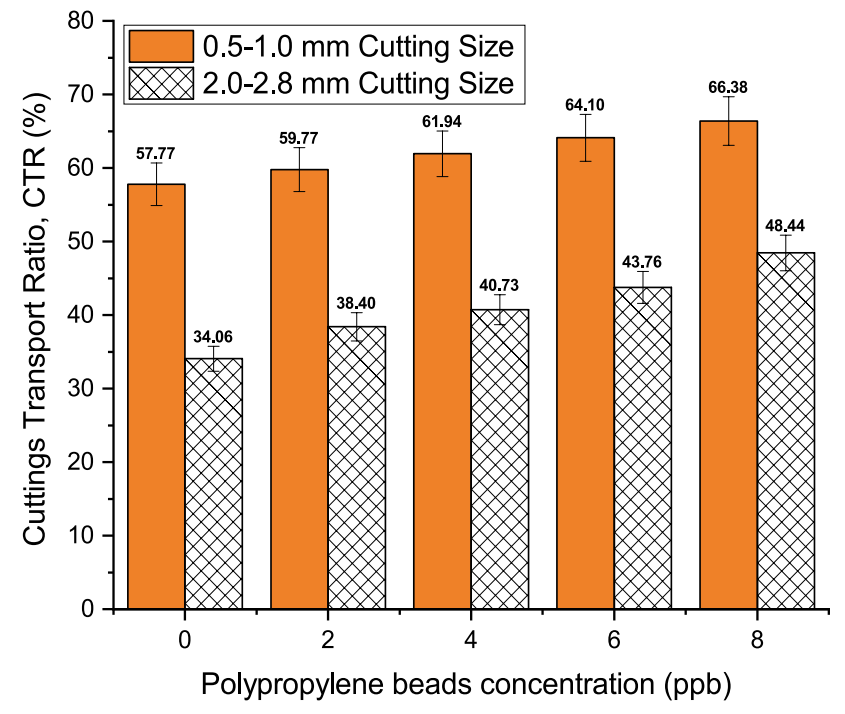

Fig. 8 CTR versus polypropylene bead concentration for both cuttings sizes with pipe rotation (120 RPM)

lifted, whereas the lifting of larger cuttings is slightly enhanced (Duan et al. 2008). In addition, pipe rotation slightly increases the CTR for both cutting sizes. For small cuttings $(0.5-1.0 \mathrm{~mm})$, the CTR increases from $54.5 \%$ to $57.8 \%$, and the CTR for larger cuttings $(2.0-2.8 \mathrm{~mm})$ increases from $25.2 \%$ to $34.1 \%$ for $0 \mathrm{ppb}$. This result indicates that pipe rotation does have a significant effect on the lifting of cuttings.

\section{Buoyancy force influence on lifting the cuttings}

According to buoyancy theory, a less dense particle floats in a dense medium, thus creating a buoyancy force. The density of polypropylene beads is $0.9 \mathrm{~g} / \mathrm{cc}$, and the beads flow in a much denser drilling fluid that has a density of $1.198 \mathrm{~g} / \mathrm{cc}$. Using the buoyancy force equation, the phenomenon of polypropylene beads creating buoyancy force can be investigated.

$F_{B}=g \cdot V_{p}\left(\rho_{f}-\rho_{b}\right)$

Equation 2 is used to determine the buoyancy force. Then, the sum volume of polypropylene beads is used in the equation to calculate the total additional buoyancy force acting on the cuttings. The results are shown in Table 3.

As shown in Table 3 and Fig. 9, the buoyancy force increases as the polypropylene bead concentration increases. This result thus verifies the increase in CTR when the polypropylene bead concentration increases, as shown in Figure 8. 
Table 3 Buoyancy force of polypropylene beads acting on cuttings

\begin{tabular}{llll}
\hline $\begin{array}{l}\text { Polypropylene con- } \\
\text { centration }(\mathrm{ppb})\end{array}$ & $\begin{array}{l}\text { Mass of beads } \\
\text { Injected }(\mathrm{g})\end{array}$ & $\begin{array}{l}\text { Volume of beads } \\
\text { Injected }(\mathrm{cc})\end{array}$ & $\begin{array}{l}\text { Buoyancy } \\
\text { force, }(\mathrm{lbs})\end{array}$ \\
\hline 0 & 0 & 0 & 0 \\
2 & 857.14 & 953.38 & 0.63 \\
4 & 1714.29 & 1904.77 & 1.25 \\
6 & 2571.43 & 2857.14 & 1.88 \\
8 & 3428.57 & 3809.52 & 2.5 \\
\hline
\end{tabular}

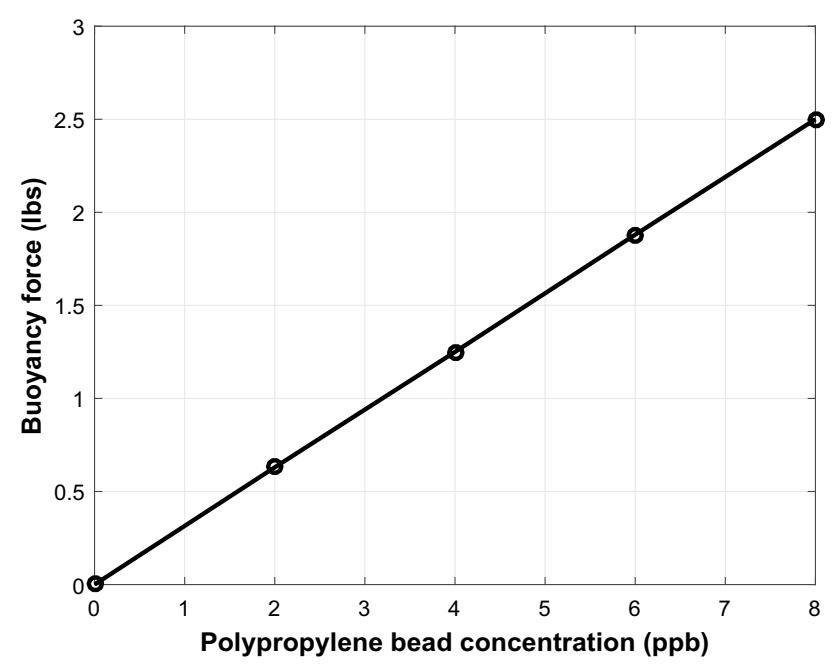

Fig. 9 Buoyancy force of polypropylene beads acting on cuttings

\section{Effect of impulsive force created from collision of polypropylene beads and cuttings}

In addition to buoyancy force, impulsive force is another reason for effective cutting lifting. This is due to the impact between cuttings and polypropylene beads that causes cuttings to be lifted. According to this experiment, the mud density is $10 \mathrm{ppg}$ (equivalent to $1.198 \mathrm{~g} / \mathrm{cc}$ ), and the annular velocity used in this experiment is $0.86 \mathrm{~m} / \mathrm{s}$. The impulsive force equation is given in Eq. 3

Impulsiveforce $=m \cdot\left(V_{f}-V_{i}\right)$

The calculated impulsive forces due to the collision between polypropylene beads and cuttings are tabulated in Table 4 .

As shown in Fig. 10, the increase in polypropylene bead concentration causes an increase in impulsive force. This result also proves that a higher polypropylene concentration causes an increase in CTR, where $8 \mathrm{ppb}$ is the largest and $2 \mathrm{ppb}$ is the lowest. In conclusion, $8 \mathrm{ppb}$ polypropylene beads result in the highest impulsive force and buoyancy forces, thus confirming that the increase
Table 4 Impulsive forces of polypropylene beads

\begin{tabular}{lc}
\hline Polypropylene concentration $(\mathrm{ppb})$ & Impulsive Force \\
\hline 0 & 0 \\
4 & -0.29 \\
6 & -0.33 \\
8 & -0.35 \\
\hline
\end{tabular}

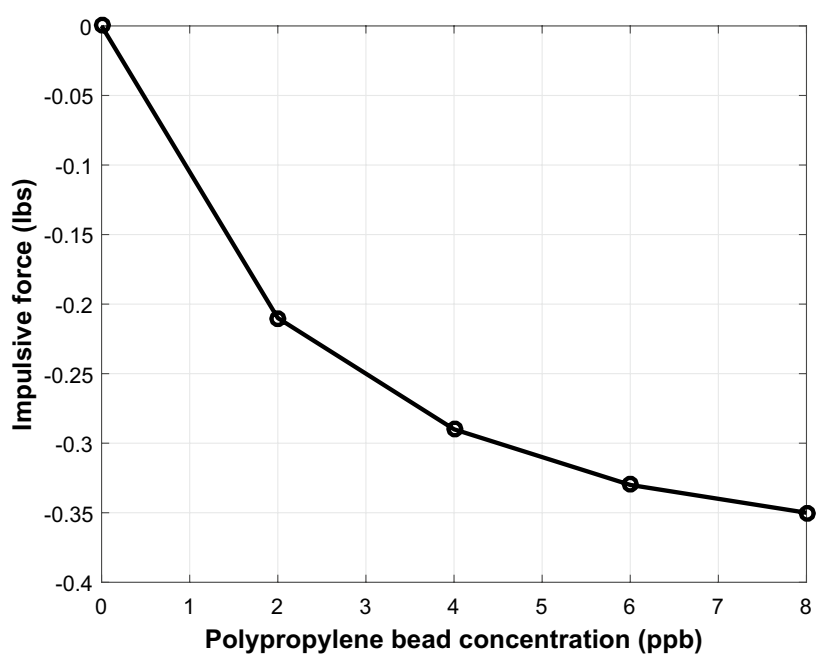

Fig. 10 Impulsive force versus polypropylene beads concentration

in polypropylene concentration directly relates to the increase in cutting lifting efficiency.

\section{Conclusions}

1. The performance of polypropylene beads is more significant at the vertical angle of $0^{\circ}$ because cuttings are uniformly distributed throughout the annular section and settle faster, whereas the worst angle is at $60^{\circ}$ because the MTV is the highest at hole angles from $40^{\circ}$ to $60^{\circ}$.

2. As the concentration of polypropylene beads increases, the CTR also increases for all hole angles, which is imperative for hole cleaning.

3. Polypropylene beads provide an increase in CTR for both smaller and larger cuttings. However, smaller cuttings provide a better yield due to the presence of PAC solution, which increases the mud carrying capacity compared to larger cuttings.

4. Pipe rotation slightly increases the CTR because the orbital motion of pipe rotation causes an increase in frictional pressure loss, thus significantly reducing stationary bed formation. 
5. With the help of pipe rotation and increased concentration of polypropylene beads, there is a drastic increase in the CTR that is efficient for hole cleaning.

6. The contribution of impulsive force and buoyancy forces is directly related to the increase in CTR.

\begin{abstract}
Acknowledgements The authors wish to express their sincere thanks to the Research Management Centre of University of Technology Malaysia and the Malaysian Ministry of Higher Learning for providing the needed funds (Vote 4F575).
\end{abstract}

Open Access This article is licensed under a Creative Commons Attribution 4.0 International License, which permits use, sharing, adaptation, distribution and reproduction in any medium or format, as long as you give appropriate credit to the original author(s) and the source, provide a link to the Creative Commons licence, and indicate if changes were made.The images or other third party material in this article are included in the article's Creative Commons licence, unless indicated otherwise in a credit line to the material. If material is not included in the article's Creative Commons licence and your intended use is not permitted by statutory regulation or exceeds the permitted use, you will need to obtain permission directly from the copyright holder.To view a copy of this licence, visit http://creativecommons.org/licenses/by/4.0/.

\section{References}

Akhshik S, Behzad M, Rajabi M (2015) CFD-DEM approach to investigate the effect of drill pipe rotation on cuttings transport behavior. J Pet Sci Eng 127:229-244. https://doi.org/10.1016/j.petro 1.2015.01.017

Amanna B, Reza M, Movaghar K (2016) Cuttings transport behavior in directional drilling using computational fluid dynamics (CFD). J Nat Gas Sci Eng 34:670-679. https://doi.org/10.1016/j.jngse .2016.07.029

Beck RW, Nuss WF, Dunn TH (1947) The flow properties of drilling muds. society of petroleum engineers, American Petroleum Institute, https://www.onepetro.org/conference-paper/API-47-009

Becker TE, Azar JJ (1985) Mud-weight and hole-geometry effects on cuttings transport while drilling directionally. Society of Petroleum Engineers, SPE Drilling and Completion

Bilgesu HI, Mishra N, Ameri S (2007) Understanding the effect of drilling parameters on hole cleaning in horizontal and deviated wellbores using computational fluid dynamics. Society of Petroleum Engineers, Eastern Regional Meeting, 17-19 October, Lexington, Kentucky USA, https://doi.org/10.2118/111208-MS

Bird J, Garrett C (1996) Co-polymer beads reduce friction in horizontal wells. J Canad Pet Technol https://doi.org/10.2118/96-09-GE

Bland RG, Mullen GA, Gonzalez YN, Harvey FE, Pless ML (2006) Modeling of effect of drill pipe rotation speed on wellbore cleanout. Society of petroleum engineers, IADC/SPE Asia Pacific drilling technology conference and exhibition, 13-15 November, Bangkok, Thailand, https://doi.org/10.2118/103731-MS

Boyou NV, Ismail I, Sulaiman WRW, Haddad AS, Husein N, Hui HT, Nadaraja K (2019) Experimental investigation of hole cleaning in directional drilling by using nano-enhanced water-based drilling fluids. J Pet Sci Eng 176:220-231. https://doi.org/10.1016/j.petro 1.2019.01.063

Clark R, Bickham K (1994) A mechanistic model for cuttings transport. Society of Petroleum Engineers, SPE Drilling and Completion, https://doi.org/10.2118/28306-MS
Duan M, Miska SZ, Yu M, Takach NE, Ahmed RM, Zettner CM (2008) Transport of small cuttings in extended-reach drilling. Society of Petroleum Engineers, SPE Drilling and Completion, https://doi. org/10.2118/104192-PA

Dushaishi MFA, Nygaard R, Stutts DS (2016) Effect of drilling fluid hydraulics on drill stem vibrations. J Nat Gas Sci Eng 35(Part A):1059-1069. https://doi.org/10.1016/j.jngse.2016.09.041

Egenti NB (2014) Understanding drill-cuttings transportation in deviated and horizontal wells. Society of Petroleum Engineers, SPE Drilling and Completion, https://doi.org/10.2118/172835-MS

Frank H, Ting R (2014) Directional drilling in unstable environments. Int J Min Sci Technol 24(3):397-402. https://doi.org/10.1016/j. ijmst.2014.03.019

Frigaard IA, Paso KG, de Souza Mendes PR (2017) Bingham's model in the oil and gas industry. Rheol Acta 56(3):259-282. https://doi. org/10.1007/s00397-017-0999-y

Gavignet AA, Sobey IJ (1989) Model aids cuttings transport prediction. J Pet Technol https://doi.org/10.2118/15417-PA

Growcock F, Frederick T, Reece A, Green G, Ruffin M (1999) Novel lubricants for water-based drilling fluids. Society of Petroleum Engineers, SPE international symposium on oilfield chemistry, 16-19 February, Houston, Texas, https://doi.org/10.2118/50710 -MS

Hakim H, Katende A, Sagala F, Ismail I, Nsamba H (2018) Performance of polyethylene and polypropylene beads towards drill cuttings transportation in horizontal wellbore. J Pet Sci Eng 165:962-969. https://doi.org/10.1016/j.petrol.2018.01.075

Hareland G, Azar J, Rampersad P (1993) Comparison of cuttings transport in directional drilling using low-toxicity invert emulsion mineral-oil-based and water-based muds. Society of petroleum engineers, low permeability reservoirs symposium, 26-28 April, Denver, Colorado, https://doi.org/10.2118/25871-MS

Hemphill T, Ravi K (2010) Modeling of effect of drill pipe rotation speed on wellbore cleanout. Society of Petroleum Engineers, IADC/SPE Asia Pacific drilling technology conference and exhibition, 1-3 November, Ho Chi Minh City, Vietnam, https://doi. org/10.2118/135703-MS

Heshamudin NS, Katende A, Rashid HA, Ismail I, Sagala F, Samsuri A (2019) Experimental investigation of the effect of drill pipe rotation on improving hole cleaning using water-based mud enriched with polypropylene beads in vertical and horizontal wellbores. J Pet Sci Eng 179:1173-1185. https://doi.org/10.1016/j.petro 1.2019.04.086

Hovda S (2019) Optimal procedures for lowering and applying weight on the bit when starting to drill. J Pet Sci Eng 174:872-879. https ://doi.org/10.1016/j.petrol.2018.11.034

Hussaini SM, Azar JJ (1974) Drill cutting transport in full scale vertical annuli. J Pet Technol https://doi.org/10.2118/10674-PA

Kamyab M, Rasouli V (2016) Experimental and numerical simulation of cuttings transportation in coiled tubing drilling. J Nat Gas Sci Eng 29:284-302. https://doi.org/10.1016/j.jngse.2015.11.022

Katende A, Boyoub NV, Ismail I, Chung DZ, Sagala F, Hussein N, Ismail MS (2019) Improving the performance of oil based mud and water based mud in a high temperature hole using nanosilica nanoparticle. Colloids and surfaces a: physicochemical and engineering aspects

Li Y, Radonjic M (2019) Microstructural comparison of the impact of drilling fluids contamination and casing corrosion on wellbore cement barriers. American Rock Mechanics Association, 53rd U.S. rock mechanics/geomechanics symposium, 23-26 June, New York City, New York, https://www.onepetro.org/conference-paper /ARMA-2019-2082

Luo, Y, Bern P, Chambers B (1994) Simple charts to determine hole cleaning requirements in deviated wells. Society of Petroleum Engineers, SPE drilling and completion, https://doi. org/10.2118/27486-MS 
Majid NFF, Katende A, Ismail I, Sagala F, Sharifa NM, Yunus MAC (2018) A comprehensive investigation on the performance of durian rind as a lost circulation material in water based drilling mud. Petroleum. https://doi.org/10.1016/j.petlm.2018.10.004

Mamat NS, Ismail I, Hashim S, Kamis A, Razak AHA (2013) The performance of polymer beads in water-based mud and its application in high-temperature well. J Pet Explor Prod Technol 3(3):151158. https://doi.org/10.1007/s13202-013-0059-9.pdf

Miswaco. Drilling Fluid Systems and Products. https://www.slb.com/ /media/Files/miswaco/catalogs/drilling_fluids_catalog.pdf, 2018. [Online; accessed 06-August-2018]

Moraveji MK, Sabah M, Shahryari A, Ghaffarkhah A (2017) Investigation of drill pipe rotation effect on cutting transport with aerated mud using CFD approach. Adv Powder Technol 28(4):1141-1153. https://doi.org/10.1016/j.apt.2017.01.020

Nazari T, Hareland G, Azar JJ (2010) Review of cuttings transport in directional well drilling: systematic approach. Society of Petroleum Engineers, SPE Western Regional Meeting, 27-29 May, Anaheim, California, USA, https://doi.org/10.2118/132372-MS

Onuoha MDU, II, PA, MNS, Ismail A (2015) Improving the cuttings transport performance of water-based mud through the use of polypropylene beads. Sains Malaysiana, 44(4):629-634, http:// journalarticle.ukm.my/8642/1/19_M.D.U._Onuoha.pdf

Oseh JO, Norrdin MNAM, Farooqi F, Ismail RA, Ismail I, Gbadamosi AO, Agi AJ (2019) Experimental investigation of the effect of henna leaf extracts on cuttings transportation in highly deviated and horizontal wells. J Pet Exp Prod Technol. https:// doi.org/10.1007/s13202-019-0631-z

Ozbayoglu M, Sorgun M, Saasen A, Svanes K (2010) Modeling of effect of drill pipe rotation speed on wellbore cleanout. J Can Pet Technol https://doi.org/10.2118/136689-PA

Ozbayoglu ME, Miska SZ, Reed T, Takach N (2004) Analysis of the effects of major drilling parameters on cuttings transport efficiency for high-angle wells in coiled tubing drilling operations. Society of Petroleum Engineers, SPE/ICoTA coiled tubing conference and exhibition, 23-24 March, Houston, Texas, https ://doi.org/10.2118/89334-MS

Ozbayoglu ME, Saasen A, Sorgun M, Svanes K (2008) Effect of pipe rotation on hole cleaning for water-based drilling fluids in horizontal and deviated wells. Society of Petroleum Engineers, IADC/SPE Asia Pacific Drilling Technology Conference and Exhibition, 25-27 August, Jakarta, Indonesia, https://doi. org/10.2118/114965-MS

Pang B, Wang S, Wang Q, Yang K, Lu H, Hassan M, Jiang X (2018) Numerical prediction of cuttings transport behavior in well drilling using kinetic theory of granular flow. J Pet Sci Eng 161:190-203. https://doi.org/10.1016/j.petrol.2017.11.028

Pang B, Wang S, Lu C, Cai W, Jiang X, Lu H (2019) Investigation of cuttings transport in directional and horizontal drilling wellbores injected with pulsed drilling fluid using CFD approach. Tunn Undergr Space Technol. https://doi.org/10.1016/j. tust.2019.05.001

Peden J, Ford J, Oyeneyin M (1990) Comprehensive experimental investigation of drilled cuttings transport in inclined wells including the effects of rotation and eccentricity. Society of Petroleum Engineers, European Petroleum Conference, 21-24 October, The Hague, Netherlands, https://doi. org/10.2118/20925-MS

Pigott RJS (1941) Transport of small cuttings in extended-reach drilling. Society of Petroleum Engineers, American Petroleum Institute, https://www.onepetro.org/conference-paper/API-41-091

Piroozian A, Ismail I, Yaacob Z, Babakhani P, Shamsul A, Ismail I (2012) Impact of drilling fluid viscosity, velocity and hole inclination on cuttings transport in horizontal and highly deviated wells. J Pet Exp Prod Technol 2(3):149-156. https://doi.org/10.1007/ s13202-012-0031-0.pdf
Rooki R, AFD, MA, NM (2018) CFD simulation of rheological model effect on cuttings transport. Journal of Dispersion Science Technology, 36(3):402-410, https://doi.org/10.1080/01932 691.2014.896219

Saboori R, Sabbaghi S, Kalantariasl A, Mowla D (2018) Improvement in filtration properties of water-based drilling fluid by nanocarboxymethyl cellulose/polystyrene core-shell nanocomposite. J Pet Exp Prod Technol 8(2):445-454. https://doi.org/10.1007/s1320 2-018-0432-9.pdf

Salehi S, Madani SA, Kiran R (2016) Characterization of drilling fluids filtration through integrated laboratory experiments and CFD modeling. J Nat Gas Sci Eng 29:462-468. https://doi. org/10.1016/j.jngse.2016.01.017

Sanchez RA, Azar JJ, Bassal A, Martins A (1999) Effect of drillpipe rotation on hole cleaning during directional-well drilling. SPE J https://doi.org/10.2118/56406-PA

Saxena A, Pathak AK, Ojha K, Sharma S (2017) Experimental and modeling hydraulic studies of foam drilling fluid flowing through vertical smooth pipes. Egypt J Pet 26(4):279-290. https ://doi.org/10.1016/j.ejpe.2016.04.006

Sayindla S, Lund B, Ytrehus JD, Saasen A (2017) Hole-cleaning performance comparison of oil-based and water-based drilling fluids. J Pet Sci Eng 159:49-57. https://doi.org/10.1016/j.petro 1.2017.08.069

Scomi. Drilling Fluids. http://www.scomigroup.com.my/GUI/pdf/ drilling_fluid.pdf, 2018. Accessed 06 Aug 2018

Shu B, Ma B (2016) The return of drilling fluid in large diameter horizontal directional drilling boreholes. Tunn Undergr Space Technol 22:1-11. https://doi.org/10.1016/j.tust.2015.11.002

Shu B, Zhang S (2018a) Cuttings transport in maxi HDD boreholes with front reaming and one way drilling mud return technologies. Tunn Undergr Space Technol 72:1-8. https://doi. org/10.1016/j.tust.2017.11.015

Shu B, Zhang S (2018b) Cuttings transport in maxi HDD boreholes with front reaming and one way drilling mud return technologies. Tunn Undergr Space Technol 72:1-8. https://doi. org/10.1016/j.tust.2017.11.015

Sifferman TR, Myers GM, Haden EL, Wahl HA (1974) Drill cutting transport in full scale vertical annuli. J Pet Technol https://doi. org/10.2118/4514-PA

Skalle P (2010) Drilling fluid engineering. Ventus Publishing Company. ISBN 978-87-403-1139-6. https://bookboon.com/en/drill ing-fluid-engineering-ebook

Sun X, Wang K, Yan T, Shao S, Jiao J (2014) Effect of drillpipe rotation on cuttings transport using computational fluid dynamics (CFD) in complex structure wells. J Pet Explor Prod Technol 4(3):255-261. https://doi.org/10.1007/s13202-014-0118-x.pdf

Walker S, Li J (2000) The effects of particle size, fluid rheology, and pipe eccentricity on cuttings transport. society of petroleum engineers, SPE/ICoTA coiled tubing roundtable, 5-6 April, Houston, Texas, https://doi.org/10.2118/60755-MS

Werner B, Myrseth V, Saasen A (2017) Viscoelastic properties of drilling fluids and their influence on cuttings transport. J Pet Sci Eng 156:845-851. https://doi.org/10.1016/j.petrol.2017.06.063

Williams C, Bruce G (1951) Carrying capacity of drilling muds. J Pet Technol https://doi.org/10.2118/951111-G

Yan X, Ariaratnam ST, Dong S, Zeng C (2018a) Horizontal directional drilling: state-of-the-art review of theory and applications. Tunn Undergr Space Technol 72:162-173. https://doi. org/10.1016/j.tust.2017.10.005

Yan X, Ariaratnam ST, Dong S, Zeng C (2018b) Horizontal directional drilling: state-of-the-art review of theory and applications. Tunn Undergr Space Technol 72:162-173. https://doi. org/10.1016/j.tust.2017.10.005

Yeu WJ, Katende A, Sagala F, Ismail I (2019) Improving hole cleaning using low density polyethylene beads at different mud

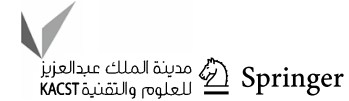


circulation rates in different hole angles. J Nat Gas Sci Eng 61:333-343. https://doi.org/10.1016/j.jngse.2018.11.012

Yi TT, Ismail I, Katende A, Sagala F, Mugisa J (2017) Experimental investigation of cuttings lifting efficiency using low and high density polyethylene beads in different hole angles. J Mater Sci Appl 3(5):71-78, http://article.aascit.org/file/pdf/8910898.pdf

Yu M, Melcher D, Takach N, Miska SZ, Ahmed R (2004) A new approach to improve cuttings transport in horizontal and inclined wells. Society of Petroleum Engineers, SPE Drilling and Completion, https://doi.org/10.2118/90529-MS

Zeng C, Yan X, Zeng Z, Yang S (2018a) The formation and broken of cuttings bed during reaming process in horizontal directional drilling. Tunn Undergr Space Technol 76:21-29. https://doi. org/10.1016/j.petrol.2017.06.063

Zeng C, Yan X, Zeng Z, Yang S (2018b) The formation and broken of cuttings bed during reaming process in horizontal directional drilling. Tunn Undergr Space Technol 76:21-29. https://doi. org/10.1016/j.tust.2018.03.008

Publisher's Note Springer Nature remains neutral with regard to jurisdictional claims in published maps and institutional affiliations. 